\title{
A RESTITUIÇÃO DO DÉCIMO SEGUNDO CAMELO: DO DIREITO À SOCIOLOGIA JURÍDICA
}

\section{THE TWELTH CAMEL RESTITUTION: FROM LAW TO SOCIOLOGY OF LAW}

\author{
${ }^{1}$ Carlos Eduardo Alban \\ ${ }^{2}$ Selmar José Maia
}

\section{Resumo}

$\mathrm{O}$ artigo propõe uma releitura dos conceitos de Niklas Luhmann partindo da obra "A restituição do décimo segundo camelo", entre eles o dos sistemas sociais autopoéticos e o enfrentamento dos paradoxos. O principal método adotado é o pragmático-sistêmico, que marca a visão do autor. Com base em uma pesquisa bibliográfica, reconstroem-se as matrizes teóricas luhmannianas que levam à ruptura com o pensamento sociológico tradicional. Conforme a análise da obra do autor, conclui-se que a Teoria Sistêmica é apta a lidar com as demandas de uma sociedade policontextural, que conta com irritações complexas em uma grande e diversificada malha de comunicação.

Palavras-chave: sistema; Luhmann, paradoxo; autopoiese.

\begin{abstract}
This article aims to review the concepts present in the article of Niklas Luhmann called "the return of the twelfth camel", including that of autopoietic social systems and the confront of the paradoxes. The method adopted is the pragmatic-systemic, which marks the author's view. Based on a literature survey, it reconstructs luhmannian theoretical matrices leading to his rupture with the traditional sociological thought. From the analysis of Luhmann's work, it is concluded that the Systemic Theory is appropriate to deal with the demands of a polycontextural society in which there are complex irritations in a large and diverse communication web.
\end{abstract}

Keywords: system; Luhmann; paradox; autopoiesis.

\section{INTRODUÇÃO}

\footnotetext{
${ }^{1}$ Mestrando em Direito Público pela Universidade do Vale do Rio dos Sinos, UNISINOS - RS, (Brasil). Bolsista integral do Programa CNPq. E-mail: kadualban@ hotmail.com

${ }^{2}$ Mestrando em Direito Público pela Universidade do Vale do Rio dos Sinos, UNISINOS - RS, (Brasil). Bolsista do Programa PROEX/CAPES. E-mail: selmarmaia.np@gmail.com
} 
A teoria dos sistemas sociais autopoiéticos de Niklas Luhmann é considerada uma das mais sofisticadas e completas construções discursivas sobre o Direito do final do século XX. Delimitações conceituais como as de autopoiese, código, função, operação, estrutura, organização, meio, forma, observação, referência e sistema trouxeram às análises jurídicas um processo cognitivo não só pós-metafísico, como também pós-ontológico de observação da realidade social. O resultado dessa inovação foi uma concepção de Direito que passou a ter a relação entre os diversos sistemas sociais autopoiéticos, sua diferenciação funcional e abertura cognitiva como seus grandes fundamentos.

A teoria de Luhmann, carecendo de outro nome melhor, pode ser enquadrada dentro do termo "pós-moderna", ao passo em que não se propõe a acentuar um ideal clássico de racionalidade, consenso ou identidade, mas a produzir diferença, fragmentação e singularidade. É uma teoria crítica, nesse sentido, avançando bem além da cientificidade disciplinarizada e de qualquer noção tradicional que a Sociologia Jurídica vinha trabalhando. Dessa forma, embora o autor continue aproveitando uma parcela das contribuições de teóricos como Weber e Parsons, a sociedade concebida por Luhmann visa à produção da diferença.

A proposta do presente artigo é analisar os principais conceitos trazidos por Luhmann a partir da sua obra “A restituição do décimo segundo camelo". Nessa esteira, buscar-se-á primeiramente a origem de uma de suas noções mais basilares da sua teoria: a própria concepção de sistemas sociais autopoiéticos. Ao contrário de outras teorias sistêmicas como a de Parsons, a obra de luhmann sofre influência direta das pesquisas dos biólogos chilenos Humberto Maturana e Francisco Varela e do seu conceito de autopoiesis, o que faz com que a depuração dessas bases e do seu conseqüente diálogo com o Direito e a Sociologia seja de grande relevância.

A segunda parte do artigo segue o exame dos sistemas sociais autopoiéticos, mas com uma ênfase maior no sistema jurídico e na ideia de autoreferência. O referido ponto conta com uma abordagem que dá enfoque à importância da comunicação para Luhmann, o qual resiste em reduzir a mesma a um mero agir comunicativo. Para tanto, segue-se uma análise da comunicação dentro de uma sociedade policontextural, na qual se faz presente uma grande malha de comunicação que liga o Direito aos mais diversos sistemas sociais em um mundo globalizado. 
Por fim, busca-se, no último capítulo, destacar a problemática do paradoxo a partir da parábola do décimo segundo camelo, tratando de sua simultânea necessidade e desnecessidade. Partindo do mesmo exemplo narrativo utilizado por Luhmann, objetiva-se trazer à tona a constituição paradoxal do próprio sistema jurídico. Nesse sentido, enfrenta-se a questão a partir da noção paradoxal de complexidade dos sistemas sociais, os quais, ao tentarem reduzir a sua complexidade, acabam por incrementá-la.

\section{A TEORIA SISTÊMICA E A AUTOPOIESE: DE MATURANA E VARELA A}

\section{LUHMANN}

Ao se adotar, na Sociologia, uma perspectiva dita sistêmica, parte-se da ideia de que a própria sociedade apresenta características e pode ser concebida como um sistema. Esse método de análise leva à compreensão dos sistemas sociais a partir da relação de interdependência entre unidades distintas, simultaneamente autônomas e dependentes, organizadas dentro de uma malha de comunicação. Como resultado dessas interações, cada sistema social é formado tanto por estruturas internas próprias como por constantes trocas com os demais sistemas (que constituem o próprio ambiente).

Em meio aos mais diversos enfoques sistêmicos, o trabalho de Niklas Luhmann é um dos que apresenta mais denso caráter transdisciplinar ${ }^{3}$. A sua teoria sobre os sistemas sociais origina-se, além de outros autores e ciências, a partir das construções teóricas dos biólogos Humberto Maturana e Francisco Varela, os quais conceberam uma capacidade de autoreprodução relacionada aos mecanismos internos de todos os seres vivos denominada autopoesis, do grego auto (mesmo) e poien (produzir). Contudo, para o sociólogo alemão não seriam apenas os sistemas vivos, mas também os sistemas psíquicos e sociais autopoiéticos.

\footnotetext{
${ }^{3}$ Para o jurista e pesquisador da Teoria Sistêmica Jean Clam, a abordagem transcidisplinar torna-se, assim, um tipo de "meio-termo", no qual a teoria tem seu própria movimento. Ou seja, é a estrutura do conjunto da sociologia luhmanniana que pode, desde então, ser qualificada de transdisciplinar, no sentido de que sua teoria se faz "ao vivo", por intermédio de uma abertura sobre a multiplicidade de teorias e de paradigmas. Ela não cessa, dessa maneira, o movimento de uma regeneração cognitiva constante. A teoria de Luhmann tem por elemento um fluxo cognitivo que a torna extremamente sensível a incidentes de estipulações e de irritações provenientes de todos os tipos de pesquisa em ciências humanas. Essa prática, de uma exploração da pesquisa tanto empírica como teórica ou epistemológica para chegar bem além e transformar seus resultados e incitações em construções de alta abstração e de um grande poder de inovação paradigmática, vai se ampliando na obra luhmanniana. Seria pelo lado da ampliação interdisciplinar de sua base de informação e de experiência, que a teoria do autor pode alcançar frente à Filosofia, uma independência e uma mutabilidade que são difíceis de serem alcançadas pela primeira. É através de um caráter que transcende as disciplinas que ela sucede a estabelecer numa escolha de abstinência axiológica e de abertura positiva ou afirmativa sobre o inaudito de formas inteiramente não intuitivas e da socialidade (CLAM, 2013, p.83).
} 
Luhmann aponta para a relação entre a autopoiese dos sistemas sociais e a sua capacidade de traçar os seus próprios contornos, visto que a reprodução exige uma distinção entre os componentes internos e externos de um sistema. Assim como nos mecanismos celulares da Biologia de Maturana e Varela, Luhmann via a sociedade a partir de uma lógica de organização sistêmica, definindo o Direito, a Economia, a Saúde, a Educação, a Política e a Religião como sistemas sociais autopoiéticos, ou seja, produtores tanto dos seus próprios limites como dos seus próprios elementos constitutivos.

A concepção original de autopoiese conferida pelos referidos autores chilenos tem natureza biológica, baseando-se numa lógica que concebe uma organização, estrutura, unidade e, consequentemente, uma autonomia dos organismos vivos através da diferenciação sistema-ambiente. A organização de um sistema representa as relações entre componentes que lhe dão sua identidade de classe (cadeira, automóvel, fábrica, ser vivo, etc.) e o modo peculiar como se realiza a organização de um sistema particular (classe de componentes e as relações concretas que se dão entre eles) é a sua estrutura (MATURANA, 1985, p.03).

Partindo dessa lógica, Maturana concebe os seres vivos como sistemas definidos por trocas estruturais determinadas pela sua própria estrutura interna. Assim, pode-se dizer que os seres vivos, apesar de não determinados diretamente por interações com o meio circundante, seriam, de alguma forma, também resultado do mesmo (MATURANA, 1985, p.02). Assim, segundo o biólogo, a conduta ou comportamento observável de qualquer ser seria, em síntese, como a coreografia de sua "dança estrutural".

Como resultado disso, segue-se que:

la conducta de un ser vivo es adecuada sólo si sus cambios estructurales ocurren en
congruencia con los cambios estructurales del medio, y esto sólo ocurre mientras su
estructura permanece congruente con el medio durante su devenir de continuo cambio
estructural. Por último, como sistemas determinados estructuralmente, los seres vivos
son sistemas que en su dinámica estructural se constituyen y delimitan como redes
cerradas de producción de sus componentes, a partir de sus componentes y de
sustancias que toman del medio: los seres vivos son verdaderos remolinos de
producción de componentes, por lo que las sustancias que se toman del medio, o se
vierten en él, pasan participando transitoriamente en el ininterrumpido recambio de
componentes que determina su continuo revolver productivo. Es esta condición de
continua producción de sí mismos, a través de la continua producción y recambio de
sus componentes, lo que caracteriza a los seres vivos y lo que se pierde en el
fenómeno de la muerte. (MATURANA, 1985, p.02-03)

A organização que define um sistema como ser vivo é a organização autopoiética. Por essa razão, um ser vivo permanece vivo enquanto a sua estrutura, quaisquer que sejam as trocas com o ambiente, realiza a sua organização autopoiética e morre se em suas trocas 
estruturais não se conserva esta organização (MATURANA, 1985, p.03). Assim, como exemplifica Maturana, um relógio de corda deixa de ser relógio (perde a sua organização como tal) se um de seus câmbios estruturais é a ruptura de sua corda. Logo, o aspecto vivo de um ser vivo seria determinado dentro dele e não fora do mesmo (MATURANA, 1985, p.03).

Todo sistema se desintegra quando em suas trocas estruturais não se conserva a sua organização. Nesse sentido, percebe-se que o que varia dentro de um sistema é a sua estrutura, sendo a sua organização um elemento invariante, o que faz com que a organização autopoiética seja comum a todos os seres vivos e um fator que os define com tais (ROCHA, 2013, p.339).

A autonomia, na teoria sistêmica, é entendida como uma capacidade de especificação das leis próprias que organizam um determinado sistema, que o define como unidade (MATURANA; VARELA, 2003, p.28), sendo a estrutura interna o que dá singularidade aos organismos. Esse princípio de separação de uma coisa do seu fundo (no caso, ambiente) representa muito mais do que uma mera distinção teórica entre uma célula e o seu entorno na Biologia de Maturana e Varela. A abordagem sistêmica acaba por traçar uma nova forma de acessar o conhecimento, o que traz à tona questionamentos acerca do próprio processo de cognição.

Ao trazer uma análise sistêmico-sociológica que compartilha da noção de autopoiese dos autores chilenos, Niklas Luhmann aborda o Direito e a sociedade através da oposição entre autorreferência e heterorreferência e em meio aos mecanismos de abertura e fechamento dos sistemas (ROCHA, 2013, p.342). Assim, um sistema autopoiético é também autoreferencial na medida em que os "seus respectivos elementos são produzidos e reproduzidos pelo próprio sistema graças a uma sequência de interação circular e fechada" (TEUBNER, 1989, prefácio, p.X-XI).

De acordo com Luhmann, uma inovação decisiva trazida pela autopoiese biológica é de conceber sistemas não só como sendo auto-organizados, ou seja, capazes de gerar a sua própria ordem a partir da interação de seus elementos constitutivos. Muito além disso, os sistemas se auto-reproduzem, sendo capazes de produzir não apenas a ordem sistêmica (estrutura), como também as próprias unidades sistêmicas básicas (elementos), o que traz à tona o seu aspecto relativo de independência em relação ao meio circundante (TEUBNER, 1989, prefácio, p.XI). 
Luhmann retoma e amplia o pensamento dos biólogos chilenos ao conceber o sistema autopoiético como tendo um duplo aspecto, sendo aquele que é "simultaneamente fechado e aberto, ou seja, algo que tem repetição e diferença, tendo que equacionar no seu interior esse paradoxo, que os operadores do Direito vão usar como critério para tomar decisões" (LUHMANN, 2004, p.38).

Assim, o autor concebe sistemas sociais que não são fechados nem abertos, já que um sistema plenamente fechado é impossível, visto que não pode haver um sistema que se autoreproduza a partir unicamente dele mesmo. Além disso, falar num sistema aberto por completo seria nem mais conceber um sistema, uma vez que não haveria a diferenciação sistema-ambiente. No fim, um sistema totalmente fechado não é possível e um completamente aberto é inútil (LUHMANN, 2004, p.38).

O sociólogo alemão afirma que o sistema jurídico, do mesmo modo que os demais sistemas sociais, não pode proceder de outra forma, pois ele está comprometido com sua autopoiesis. Dessa forma, a autopoiese é igualmente condição e resultado da evolução do sistema, sendo, assim, nas palavras de Luhmann, "a forma da evolução da evolução" (LUHMANN, 2004, p.67). Na verdade, mais do que um sistema, o Direito representaria um dos subsistemas da sociedade. Nesse sentido, a autopoiese do sistema jurídico é uma continuação da autopoiese da sociedade (SCHWARTZ, 2009, p.103).

Nesse ínterim, um subsistema funcionalmente diferenciado, ou como classifica o sociólogo Gunter Teubner, um sistema de segunda ordem, somente pode se desenvolver quando produz seus próprios elementos para si mesmo de maneira exclusiva. Desse modo, o sistema jurídico vai produzir diferença e reiniciar ciclicamente a sua autopoiese mediante a repetição do seu elemento básico: a decisão. É o próprio Direito que define as suas premissas de validade por intermédio de uma norma jurídica e das decisões judiciais (TEUBNER, 1989, p.221).

Ademais, é também imprescindível para compreender o conceito de autopoiese a presença de um "observador", ou seja, alguém externo que pode fazer diferenciações e especificar a organização e estrutura daquilo que distingue como algo diferente de si mesmo (MATURANA, 1995, p. 228-229). Esse observador deve sempre realizar esses processos de identificação através de seus próprios mecanismos cognitivos, como sendo, ele mesmo, um sistema psíquico operativamente diferenciado e fechado. 
Uma das noções mais centrais da teoria de Luhmann é a sua perspectiva própria relativa à comunicação. Para o autor, os sistemas sociais são sistemas comunicativos que se reproduzem por estarem, constantemente, ligando comunicações a comunicações. Por conseguinte, cada sistema social seria composto por um conjunto de múltiplas comunicações e não de "seres humanos acoplados", como compreendia Maturana (KING, Michael, 2009, p.78), já que os indivíduos, segundo Luhmann, encontram-se no ambiente/meio da sociedade, não sendo componentes da mesma. As pessoas seriam sistemas psíquicos ligados à consciência que produzem pensamento, sendo que apenas a comunicação produz comunicação (NEVES, 1997, p. 16-17).

$\mathrm{Na}$ sua teoria, a comunicação realiza-se mediante uma relação circular entre estrutura e operações comunicativas, uma vez que as estruturas só podem ser criadas e modificadas por meio de operações, as quais se especificam devido às estruturas. Assim, uma função de encarar o Direito como um sistema social é a de buscar uma identificação daquela comunicação especificamente jurídica, o que depende de uma prévia diferenciação da sua estrutura.

\section{A (IM)POSSIBILIDADE DA COMUNICAÇÃO DO DIREITO NA SOCIEDADE POLICONTEXTURAL}

Em sua reformulação das bases sociológicas, Luhmann pretende que se leve a sério um pressuposto básico da Sociologia: tudo está incluído dentro da sociedade, não sendo possível nenhuma produção de identidade ou linguagem que não seja dentro do seu interior. A sociedade criou comunicações, em outras palavras, linguagens ou modelos, ou melhor, sistemas, os quais ordenam a sua complexidade conforme o tipo de evolução funcional evolutivamente consagrado (ROCHA, 2009, p.19)

O termo globalização, sempre em voga nas últimas décadas, representa um fenômeno complexo, plural, policontextural ${ }^{4}$. Os efeitos da contemporaneidade provocaram e continuam

\footnotetext{
${ }^{4}$ Por policontexturalidade podemos compreender uma metáfora dotada de um valor eurístico para a observação de vários sistemas (Política, Economia, Saúde, Educação, Direito, Religião) que atuam segundo racionalidades específicas e, sobretudo, levam à produção de ressonância nos demais sistemas através da utilização de instrumentos jurídicos, num processo social co-evolutivo. Para mais informações sobre a policontexturalidade e seus efeitos, sugere-se a leitura do artigo a perspectiva sistêmica autopoiética nas relações contratuais frente à contemporaneidade dos autores Leonel Severo Rocha e Selmar José Maia. Disponível em: ROCHA, Leonel Severo; MAIA, Selmar José. In: Luciana Costa Poli; César Augusto de Castro Fiuza; Elcio Nacur Rezende
} 
provocando grandes alterações nas mais diversas áreas do conhecimento humano. Por certo, esse fator desencadeia uma mudança drástica nas relações pessoais em sociedade. Para tanto, a comunicação ganha papel fulcral em uma era globalizada.

Em outras palavras, para Luhmann:

la sociedad es el concepto social más amplio, incluye todo lo social y, por consiguiente, no conoce ningún entorno social. Si se agregan factores sociales, se surgen interlocutores o temas de comunicación novedosos, la sociedad crece, pues esos factores arraigan en la sociedad, no pueden ser externalizados ni tratarse como una cosa de un entorno, ya que todo lo que es comunicación es sociedad (LUHMANN, 1998, p.408).

Para Leonel Severo Rocha, "a sociedade como sistema social se constitui e se sustenta por intermédio "da comunicação". Por sua vez, a comunicação depende da linguagem, das funções, da diferenciação e das estruturas, gerando a evolução social (ROCHA, 2013, p.35)". Nesse sentido, destaca-se que Luhmann é, sem sombra de dúvidas, um dos júris-sociólogos que mais contribuiu para a análise no que tange aos sistemas sociais e o seu entorno.

Nesse sentido, como se sabe, a Teoria da Sociedade aperfeiçoada por Niklas Luhmann, levou em consideração como fator primordial a comunicação na atual sociedade policontextural. Para tanto, desenvolveu-se uma teoria da comunicação que permite entender os processos na interação, organização e sociedade.

Nas palavras de Luhmann,

A teoria tradicional concebia os sistemas complexos como (todos), constituídos por
(partes). A ideia base era a de que a ordem do todo explica qualidades que as partes
isoladas nunca poderiam possuir por si próprias. A teoria dos sistemas recente, tal
como a vejo, abandonou a sua perspectiva tradicional introduzindo um referência
explícita ao ambiente. A noção de ambiente não somente que algo mais existe fora do
sistema em estudo. Não se trata de distinguir entre (aqui) e (em qualquer outro sítio).
A nova tese, em vez disso, propõe o seguinte: as estruturas e processos de um sistema
só são possíveis em relação a um ambiente, e só podem ser entendidas se estruturadas
nesta relação. Assim é, pois só por referência a um ambiente é possível distinguir
(num sistema dado) algumas funções como um elemento e outras funções como uma
relação entre elementos. Exagerando um pouco, podemos até dizer que um sistema é a
sua relação com o ambiente, ou que é a diferença entre sistema e ambiente
(LUHMANN, 2001, p.99-100).

A partir desse entendimento, afastou-se a tradição sociológica acostumada a entender que o átomo da sociedade é a ação. Em outras palavras, a comunicação é necessariamente social, enquanto a ação deve ser adjetiva - como a ação comunicativa - a fim de se tornar um elemento da sociedade (RODRIGUEZ, 2005, p.27). Nesse sentido, é necessário destacar que a

(Orgs.). Direito Civil - XXII Encontro Nacional do CONPEDI/UNINOVE. FUNJAB: São Paulo, 2014. p. 208,222 . 
Teoria Pragmática-Sistêmica de Luhmann parte da análise da Teoria dos Sistemas de Parsons, todavia, nos últimos anos de sua vida, o sociólogo voltou-se para uma perspectiva autopoiética, acentuando a sistematicidade do Direito como auto-reprodutor de sua categoria (ROCHA, 2005, p.30-31).

Para Darío Rodríguez, a partir dessa análise sistêmica, é possível identificar que o sentido e a forma de processamento da complexibilidade são, também, dimensões da própria complexibilidade. Em outras palavras, estas dimensões do sistema são acessíveis pelo próprio sistema (RODRIGUEZ, 2005, p.27). Por se tratar o Direito de um sistema autoreprodutor, implica que suas operações sejam autorreferentes, ou seja, suas decisões se referem a si mesmas, dentro do próprio sistema jurídico. Ademais, essa diferença funcional somente é possível por o Direito ser encarado como um sistema autopoiético, em outras palavras, operacionalmente fechado e autorreferente.

Ao se debruçar sobre as peculiaridades do sistema jurídico, Günter Teubner aponta que:

[...] o Direito é um sistema social autopoético de comunicação, que se autonomizou do sistema social geral graças à emergência de um código próprio e diferenciado suficientemente estável para funcionar como centro de gravidade e princípio energético de um processo de auto-reprodução recursiva, fechada e circular de comunicações especificamente jurídicas (TEUBNER, 1989, p. 21).

Falar em fechamento operacional não significa que o Direito está separado por completo da sociedade e dos de mais subsistemas. Representa apenas que é o próprio sistema do Direito quem define seus limites e o que é relevante ao seu entorno e, também, quais irritações do ambiente poderão desencadear mudanças em si próprio (RODRIGUEZ, 2005, p.53).

Todavia, na sociedade policontextural, perfila-se um problema importante, ou seja, em determinados âmbitos da sociedade o código ou Direito não pode ser aplicado, surgindo-se um metacódigo de inclusão/exclusão (RODRIGUEZ, 2005, p.53). Nesse sentido, depara-se, sobretudo, com os limites do Direito, os quais são enfrentados por Niklas Luhmann da seguinte maneira:

Enfrentamos al famoso problema de si estos límites se establecen de modo analítico o en modo concreto; es decidir, si se establecen mediante un observador o mediante el objeto mismo. Si se responde: "de modo analítico" - y algunos creen erróneamente estar obligados a ello por razón de que están situados en la teoría científica -, entonces se concede a cualquier observador el derecho a su propia objetividad. De esta manera nos encontramos otra vez ahí en donde se constata la imposibilidad de una conversación interdisciplinaria. Por eso nosotros respondemos: "por medio del objeto". Esto lleva directamente a afirmar: el derecho mismo determina cuáles son los límites del derecho. El derecho mismo determina, por lo 
tanto, qué es lo que pertenece al derecho y qué es lo que no. Las divergencias de opiniones se trasladan, entonces, hacia la pregunta: cómo ocurre esto (LUHMANN, 2005, p.67-68).

Conforme se verifica nas palavras anteriores, é possível identificar um caminho através de quatro pontos que respondem a respectiva problemática. Primeiramente, arrisca-se dizer que, atualmente, a teoria que melhor descreve algo que produz seus próprios limites em relação ao seu entorno é a teoria dos sistemas. Segundo, recusada a opção "analítica" para a determinação dos limites, far-se-á necessário organizar uma observação de segundo plano, ou seja, deve-se observar um objeto como se tratando de um observador que se oriente como um objeto.

Terceiro, com o conceito de sistema observador, explorar-se-á um caminho epistemológico construtivista. Por último, mas não menos importante, abrem-se as possibilidades de se distinguir uma forma de observação jurídica do Direito de outra sociológica, a qual observara o Direito de fora e transcende os limites de uma auto-observação sistêmica (LUHMANN, 2005, p.68).

\section{O DIREITO COMO SISTEMA AUTOPOIÉTICO PARADOXAL NA SOCIEDADE COMPLEXA}

Primeiramente, a metáfora do Décimo Segundo Camelo, utilizada por Niklas Luhmann para exemplificar a presença de paradoxos no cotidiano profissional do subsistema do Direito, parte de uma lógica binária da necessidade/não necessidade. Nesse ínterim, o Direito seria paradoxalmente constituído, por isso simultaneamente ele é e não é necessário (LUHMANN, 2004, p.33-34).

Com efeito, para explicar sua teoria, Luhmann utiliza uma parábola contando a história de um rico beduíno que, após sua morte, o seu patrimônio foi repartido entre os seus três filhos. Assim, realizou-se o processo sucessório através de testamento, deixando para os três herdeiros onze camelos que deveriam ser partilhados conforme os preceitos estipulados pela religião daquela comunidade, o que levaria em consideração a idade de cada um dos filhos. 
Para tanto, determinou-se que o primeiro filho, Achmed, deveria receber a metade dos camelos. Já o segundo filho, Ali, ficaria com um quarto destes. Por fim, o terceiro filho, Benjamin, sendo o mais novo, teria o direito de receber apenas um sexto dos camelos (LUHMANN, 2004, p.33-34). Com a morte do beduíno, Achmed, seu filho mais velho, reivindicou seis camelos, o que fez com que seus outros irmãos logo protestassem, visto que isto representaria mais do que lhe era de direito: a metade dos mesmos.

O conflito foi levado ao juiz, que ofertou um de seus camelos aos herdeiros a fim resolver o presente problema. O magistrado arguiu, ainda, que, se Alá assim o quisesse, estes restituiriam o seu camelo. Desta forma, com doze camelos, os irmãos puderam iniciar a divisão, sendo que Achmed recebeu metade, ou seja, seis camelos, Ali ganhara seu um quarto, isto é, três, e Benjamin percebeu seu um sexto, dois. Portanto, procedendo através desse jogo matemático, os onze camelos foram partilhados e o décimo segundo fora devolvido ao juiz (LUHMANN, 2004, p.33-34).

Ao partirmos da parábola anterior, é possível perceber que, ao observarmos as questões de uma segunda ordem, teremos resultados totalmente diferentes, ou seja, paradoxais. Para tanto, Leonel Severo Rocha explica que:

"[...] não é possível, nas sociedades complexas, uma ruptura radical entre passado e futuro. Assim, algumas questões do normativismo podem estar ainda muito presentes em certas questões e, para outras, não fazerem nenhum sentido [...] existem passagens, portais, que se fecham e não fecham. Depende sempre da observação do problema. [...] Do ponto de vista temporal, eventos do passado ainda estão presentes aqui, hoje, e outros já desapareceram" (ROCHA, 2009, p.35).

Nesse sentido, é possível notar que a complexidade torna-se cada vez mais incrementada no momento em que se tenta reduzir sua própria complexidade. Em outras palavras "a introdução de uma referência externa então assimetriza esse paradoxo. Há princípios, há valores, há consequências etc. Mas o paradoxo não se resolve. Ele apenas se desdobra para novas configurações (BAHIA; SIMIONI, 2010, p.03)”.

Focada nessas observações, Juliana Neuenschwander Magalhães diz a respeito desta irresolução dos paradoxos que:

o grande desafio da lógica contemporânea é o de descrever, de maneira não paradoxal, que a realidade é paradoxal. A epistemologia construtivista realiza isto a partir da assunção do paradoxo, partindo da afirmação de que não existe um observador último, capaz de conhecer uma verdade última. Desta forma, o construtivismo se resolve em uma rede recursiva de observações sobre observações, que não pretendem refletir a realidade mas que, por outro lado, são submetidas a condições extremamente restritivas, que são se auto-regulam, constituindo estados que sejam compatíveis com estas (MAGALHÃES, 2013, p.292). 
Por conseguinte, ainda com relação aos paradoxos do e no direito, percebe-se que estes constituem a forma como observamos as acomodações auto-referenciais no interior do sistema. Podemos, portanto, em um primeiro momento, nos guiar pela norma e decisão, ou seja, por meio das normas alcançaremos o objeto da decisão, os quais seguem as próprias normas, após serem textualizados, tornando-se objetos das próprias decisões (LUHMANN, 2004, p.36).

Em outras tintas, as normas tornam as decisões possíveis porque as decisões tornam as normas possíveis. Ademais, frisa-se que este processo resulta em um circulo de autoreferência. A decisão somente é uma decisão, se reage às expectativas da norma, cumprindoa, e apresentando, também, um leve desvio em relação a ela mesma. Inversamente, a norma não seria norma, caso a decisão não fosse produzida (LUHMANN, 2004, p.36-37). Nesse sentido, o décimo segundo camelo é um modo de operacionalização desse paradoxo.

Ainda, Luhmann, destaca que:

\begin{abstract}
A exigência do décimo segundo camelo remete-nos e este problema, em que se sugere uma certeza que não é propriamente adquirida. O sistema utiliza camelos sem o possuir. As operações de empréstimo e restituição simbolizam esta ambivalência. O sistema fornece a possibilidade de se orientar pelo camelo como critério fixo de decisão, [muito] embora se reserve igualmente a possibilidade de operar com premissas flutuantes (LUHMANN, 2004, p.35).
\end{abstract}

Destarte, é importante destacarmos também, sobre o termo paradoxo nas sistemáticas autopoiéticas que este "refere-se a um fenômeno da observação e da descrição - [...]. A observação dos paradoxos bloqueia a observação e a descrição do sistema, embora a própria autopoiesis do sistema continue às cegas (MAGALHÃES, 2013, p.292)". Portanto, há uma busca ou não, da presença do Décimo Segundo Camelo nas operações do subsistema do Direito e a condução desta a um raciocínio errôneo ou adequado das decisões judiciais. Numa palavra, o camelo é e não é necessário. De igual sorte, a pesquisadora Juliana Magalhães ensina a respeito do paradoxo presente nas teorias clássicas do Direito.

Nesse sentido, ao observarmos essas teorias, num nível superior de observação de suas observações, então podemos ver que elas têm se caracterizado pela tentativa de evitar o encontro com esse paradoxo, lançando mão de instrumentos semânticos provisórios e ineficientes (MAGALHÃES, 2013, p.295). Dessa forma, pode-se entender que é na Teoria dos Sistemas que a autorreferência ocorre, o que causa, por sua vez, o paradoxo. Isso possibilita, inclusive, que os sistemas sociais se desparadoxem, o que permite a inclusão de 
assimetrias que, posteriormente, proporcionam a capacidade de se reconectar operações a operações (MAGALHÃES, 2013, p.295).

Ainda, podemos compreender que uma cooperação entre dois subsistemas, por exemplo, o jurídico e o sociológico, "pressupõe que a teoria reconheça as coisas que previamente deu por supostas a partir de sua função de "desparadoxação". Ou seja, "a Teoria do Direito pode também transformar o paradoxo em uma qualidade do Direito" (MAGALHÃES, 2013, p.295-296).

Nesse mesmo sentido, aponta Günter Teubner que a chave para os problemas de indeterminação originados pelos paradoxos presentes nos sistemas sociais reside na chamada "desparadoxização dos paradoxos", ou seja, "na aplicação criativa dos paradoxos, na transformação de uma informação infinita em finita e de uma complexidade indeterminada numa complexidade determinada" (TEUBNER, 1989, p.24).

Nesse diapasão, novamente Rocha destaca que o Direito deve estar:

\begin{abstract}
Preparado para reconhecer e identificar todo o conjunto de fenômenos permanentes de auto-referência, paradoxo e contradições que permeiam o sistema jurídico. Esses paradoxos são inerentes à realidade do Direito e não podem ser suplantados por uma simples postura crítica (a qual apenas demonstra a existência de paradoxos dentro do sistema do Direito) ou por uma tentativa de suplantá-los mediante uma nova distinção, mas sim pela constatação de que os elementos que compõem o sistema do Direito - ações, normas, processos, realidade jurídica, estrutura, identificação constituem-se circularmente, além de vincularem-se uns aos outros também de forma circular (ROCHA, 2005, p.43).
\end{abstract}

Ademais, é fulcral compreendermos que a desparadoxização dos paradoxos e sua realidade circular do Direito nos possibilita realizar "um fechamento operativo, no qual o Direito atua auto-referencialmente com seus elementos internos [...]. Entretanto, com o escopo de orientar a [...] codificação binária [...], o sistema se abre para a influência do sistema social ou de outros sistemas parciais (Economia, Política, Religião, Saúde, Educação, Ciência)" (ROCHA, 2005, p.247).

Todavia, esta abertura somente é possível “devido à clausura operativa, pois quanto maior o fechamento de um sistema, mais estável e apto estará este a uma abertura cognitiva (sensorial). [...] apenas adquirindo relevância sistêmica e sendo internalizadas por este quando passíveis de adequação à codificação binária, obtendo um sentido jurídico" (ROCHA, 2005, p.247). Assim sendo, entende-se, no que diz respeito ao subsistema do Direito e seus paradoxos circulares, que estes devem ser capazes de produzir sua própria autoprodução, depois de plantados os elementos necessários, ou seja, estarem aptos a se (re)alimentar, 
possibilitando ao mesmo tempo, também, a capacidade de se auto-gerenciar (ROCHA, 2005, p.44).

De igual sorte, é preciso frisar que, no subsistema do Direito, temos como a organização mais relevante, por se encontra no centro de todo o diálogo, o Poder Judiciário, que possui a desparadoxização como função basilar, ou seja, necessita tomar decisões frente às incertezas (ROCHA, 2009, p.37). Alem disso, numa palavra final, arrisca-se dizer que é devido à existência de certos paradoxos que ocorrem determinadas crises no grande sistema (sociedade), bem como nos demais subsistemas sociais.

\section{CONSIDERAÇÕES FINAIS}

Conforme foi possível verificar durante a pesquisa, o ponto central em que Luhmann pauta-se ao abordar a parábola do décimo segundo camelo é o paradoxo presente no sistema jurídico, que é, ao mesmo tempo, necessário e desnecessário para a sua operabilidade. $\mathrm{O}$ décimo segundo camelo acaba, assim, funcionando não como um símbolo, mas como a própria condição de execução de uma operação simbólica. Luhmann usa dessa metáfora para tratar da própria auto-referência presente no sistema jurídico e do paradoxo que surge dentro de um sistema que dá razão a si mesmo.

Em outras palavras, por tratar da necessidade de comunicação do sistema jurídico com os demais sistemas e das limitações presentes em uma observação presa a uma visão estritamente interna realizada pelo jurista. Para o funcionamento dos sistemas sociais autopoiéticos em uma sociedade policontextural, tornam-se necessárias as estruturas e a diferenciação presente entre os sistemas e o ambiente que o circunda, ou seja, entre estruturas internas e externas, em meio à relação mista de fechamento operacional e abertura cognitiva.

Nesse sentido, a presença de um observador que consiga estabelecer os limites estruturais de um sistema é essencial. Ainda, é possível perceber que na Teoria dos Sistemas Sociais a autorreferência ocorre, o que causa, por sua vez, o paradoxo. Isso possibilita que os sistemas sociais se desparadoxem, permitindo, inclusive, a permissão de assimetrias que, posteriormente, possibilitam a capacidade de se reconectar operações a operações. 
Ainda com relação aos paradoxos do Direito, verifica-se que estes constituem a possibilidade de como analisamos as acomodações auto-referenciais no interior do sistema. Podemos, assim, nos guiar pela norma e decisão. Ou seja, por meio das normas alcançaremos o objeto da decisão, os quais seguem as próprias normas, após serem textualizados, tornandose objetos das próprias decisões. No fim, como foi possível perceber, as normas tornam as decisões possíveis porque as decisões tornam as normas possíveis.

Ainda, frisa-se que este processo resulta em um circulo de auto-referência. A decisão somente é uma decisão, se reage às expectativas da norma, cumprindo-a, e apresentando, também, um leve desvio em relação a ela mesma. Inversamente, a norma não seria norma, caso a decisão não fosse produzida. Em outros termos, para Luhmann, o décimo segundo camelo é um modo de operacionalização desse paradoxo. 


\section{REFERÊNCIAS BIBLIOGRÁFICAS}

BAHIA, Alexandre Gustavo Melo Franco; SIMIONI, Rafael Lazzarotto. HABERMAS E LUHMANN: Decisões judiciais devem fazer diferença. Consultor Jurídico. São Paulo: 12 mai. 2010, p. 03. Disponível em: <http://www.conjur.com.br/2010-mai-12/decisoes-juridicaslevar-serio-valores-principios-constitucionais?pagina=3>. Acesso em: 16 jul. 2016.

CLAM, Jean. A autopoiese no Direito. In: ROCHA, Leonel Severo; SCHWARTZ, Germano; CLAM, Jean. Introdução à teoria do sistema autopoiético do Direito. Porto Alegre: Livraria do Advogado, 2013.

KING, Michael. A verdade sobre a autopoiese no Direito. In: ROCHA, Leonel Severo; KING, Michael; SCHWARTZ, Germano. A verdade sobre a autopoiese no Direito. Porto Alegre: Livraria do Advogado, 2009.

LUHMANN, Niklas. A improbalidade da comunicação. Tradução: Anabela Carvalho. Editora Vega, 2001, $3^{\text {a }}$ ed.

LUHMANN, Niklas. A Restituição do Décimo Segundo Camelo: Do Sentido de uma Análise Sociológica do Direito. In: ARNAUD, André-Jean; JUNIOR, Dalmir Lopes (Org.). Niklas Luhmann: Do Sistema Social à Sociologia Jurídica. Rio de Janeiro: Ed. Lumen Juris, 2004.

LUHMANN, Niklas. O direito da sociedade. Tradução Saulo Krieger; tradução das citações em latim Alexandre Agnolon. - São Paulo: Martins Fontes - selo Martins, 2016.

LUHMANN, Niklas. Sociologia do Direito I. Tradução de Gustavo Bayer. - Rio de Janeiro: Edições Tempo Brasileiro, 1983.

MAGALHÃES, Juliana Neueschwander. O uso criativo dos paradoxos do direito: a aplicação dos princípios gerais do direito pela corte de justiça europeia. In: ROCHA, Leonel Severo (Org.). Paradoxos da auto-observação: percursos da teoria jurídica contemporânea. Ijuí: Ed. Unijuí, 2013, 2. ed. rev. e atual. 
MATURANA, Humberto. La Realidad: ¿objetiva o contruida? Barcelona: Anthropos, 1995.

MATURANA, Humberto. VARELA, Francisco. El árbol del conocimiento:las bases biológicas del entendimiento humano. Buenos Aires: Lumen, 2003.

MATURANA. Humberto. Biologia del fenômeno social. 1985. Disponível em: < http://cursa.ihmc.us/rid=1222211164487_1096004227_6868/social_phen_biology.pdf>.

Acesso em 15 jul. 2016.

NEVES, Clarissa Eckert Baeta. Niklas Luhmann e sua obra. In: Niklas Luhmann: a nova Teoria dos Sistemas/ Org. por Clarissa Eckert Baeta Neves e Eva Machado Barbosa Samios. - Porto Alegre: Ed. Universidade/UFRGS, Goethe-Institut/ICBA, 1997.

ROCHA, Leonel Severo. Da epistemologia jurídica normativista ao construtivismo sistêmico. In: ROCHA, Leonel Severo; SCHWARTZ, Germano; CLAM, Jean. Introdução à teoria do sistema autopoiético do Direito. Porto Alegre: Livraria do Advogado, 2005.

ROCHA, Leonel Severo. Direito Ambiental e Aupoiese. Leonel Severo Rocha, Francisco Carlos Duarte. $1^{\text {a }}$ ed. Curitiba: Juruá, 2012.

ROCHA, Leonel Severo. Observação sobre a observação Luhmaniana. In: ROCHA, Leonel Severo; KING, Michael; SCHWARTZ, Germano. A verdade sobre a autopoiese no Direito. Porto Alegre: Livraria do Advogado, 2009.

ROCHA. Leonel Severo. Teoria dos Sistemas Sociais Autopoiéticos: perspectivas de uma matriz jurídica contemporânea. Paradoxos da auto-observação: percursos da Teoria Jurídica Contemporânea, 2ed., Ijuí: Unijuí, 2013.

RODRIGUES, Darío. Invitación a la sociologia de Niklas Luhmann. In: LUHMANN, Niklas. El derecho de la sociedad. México: Herder, 2005.

SCHWARTZ, Germano. Autopoiese e direito: auto-observações e observações de segundo grau. In: ROCHA, Leonel Severo; KING, Michael; SCHWARTZ, Germano. A verdade sobre a autopoiese no Direito. Porto Alegre: Livraria do Advogado, 2009

TEUBNER, Gunther. As Múltiplas Alienações do Direito: sobre a mais-valia social do décimo segundo camelo. In: ARNAUD, André-Jean; LOPES JR. Dalmir (Org.). Niklas Luhmann: Do Sistema Social à Sociologia Jurídica. Rio de Janeiro: Lúmen Júris, 2004.

TEUBNER, Gunther. Direito, Sistema e Policontexturalidade. Piracicaba, SP: Universidade Metodista de Piracicaba - Campus de Taquaral, 2005.

TEUBNER, Gunther. O direito como um sistema autopoiético. Lisboa: Fundação Calouste Gulbenkian. 1989. 